\title{
EMPREENDEDORISMO FEMININO: CARACTERÍSTICAS E PERFIL DE GESTÃO EM PEQUENAS E MÉDIAS EMPRESAS
}

\author{
FEMALE ENTREPRENEURSHIP: CHARACTERISTICS AND \\ MANAGEMENT PROFILE IN SMALL AND \\ MEDIUM-SIZED ENTERPRISES
}

\begin{abstract}
Cibele Barsalini Martins ${ }^{1}$, Luciana Helena Crnkovic ${ }^{2}$, Nadia Kassouf Pizzinatto ${ }^{3}$ e Emerson Antonio Maccari ${ }^{4}$
\end{abstract}

\section{Resumo}

A crescente participação das mulheres na área de empreendedorismo possibilita vislumbrar um futuro em que ambos os gêneros venham a atuar nesta área em situação de equilíbrio. A concretização dessa possibilidade, considerando o cenário econômico brasileiro para os próximos anos, representaria mais do que uma perspectiva particularmente otimista, mas um acontecimento necessário, tendo em vista a exigência de crescimento da economia brasileira. Neste artigo têm-se dois objetivos: primeiro, conhecer as características pessoais de empreendedoras relacionadas à sua origem, trajetória educacional, experiência profissional e vida pessoal e, posteriormente, a identificação de parâmetros que descrevam o papel da mulher empreendedora nas pequenas e médias empresas. O método de trabalho baseou-se em uma abordagem exploratório-descritiva e estudos multicasos; e a análise dos dados utilizou a metodologia Big Five Personality Model. Durante a pesquisa realizada ficou evidente que os obstáculos são inúmeros e aparentemente insolúveis. No entanto, todas as empreendedoras entrevistadas mostraram uma marca em comum: determinação para perseguir objetivos, alcançar metas e superar dificuldades, mas é inegável que a vida particular das empreendedoras foi afetada de modo diferenciado.

Palavras-chave: Empreendedorismo feminino; Gestão; Pequenas e médias empresas.

1 Doutoranda em Administração pela UNINOVE, Mestre em Administração pela UNINOVE, Professora e Coordenadora. E-mail: cibelebm@uol.com

2 Doutoranda em Administração pela UNINOVE, Mestre em Engenharia de Produção pela Escola de Engenharia de São Carlos, Professora na Universidade Camilo Castelo. E-mail: crnkovic20@yahoo.com.br

3 Doutora e Mestre em Administração pela FGV, Administradora, Economista e Professora do Programa de Mestrado e Doutorado em Administração da Universidade Nove de Julho. E-mail: nkp@merconet.com.br

4 Doutor em Administração pelo Programa de Pós-Graduação em Administração - PPGA/FEA USP. É coordenador do Programa de Mestrado Profissional em Administração: Gestão de Projetos na Universidade Nove de Julho. Email: emersonmaccari@gmail.com 


\begin{abstract}
The growing participation of women in the entrepreneurship area enables envision a future in which both genders will act in this area in a equilibrium state. The realization of this possibility, considering the Brazilian economy scenario for the coming years, represents more than a particularly optimistic view, but a necessary event in the view of the growth requirement in the Brazilian economy. In this article have been twofold: firstly, to know the entrepreneur's personal characteristics related to their origin, educational history, professional experience and personal life and secondly, the identification of parameters that describes the role of entrepreneurship women in small and medium enterprises. The working method was based on an exploratorydescriptive approach and multi-case studies and data analysis used the Big Five Personality Model methodology. During the research it became evident that the obstacles are many an $d$ seemingly insoluble. However, all the entrepreneurs interviewed showed a mark in common: determination to pursue goals, achieving goals and overcoming difficulties, but it is undeniable that the private life of the entrepreneurs was affected differently.

Keywords: Female Entrepreneurship; Management; Small and medium-sized enterprises.
\end{abstract}

\title{
1 Introdução
}

Um movimento de mudança cada vez mais intenso vem sendo percebido na sociedade contemporânea com o aumento da participação das mulheres no mercado de trabalho, revelando uma tendência de equilíbrio no espaço de homens e mulheres no ambiente empresarial e isso não é diferente no universo da pequena empresa.

A crescente participação das mulheres, também na área de empreendedorismo, possibilita, ainda, vislumbrar um futuro em que ambos os gêneros venham a atuar neste contexto em situação de equilíbrio. A concretização desta possibilidade, considerando o cenário econômico brasileiro para os próximos anos, representaria mais do que uma perspectiva particularmente otimista, mas um acontecimento necessário, tendo em vista a exigência de crescimento da economia brasileira.

Tem-se como pressuposto, então, que as mulheres atuantes nesse setor reconhecem no empreendimento a opção de vida mais promissora, no que diz respeito à busca por crescimento profissional e realização pessoal. Consideram-no um investimento que compreende, via de regra, além do aspecto financeiro, a (intensa) dedicação, com relação aos aspectos de tempo e empenho pessoal. A leitura de periódicos e publicações especializadas (GRZYBOVSKI; BOSCARIM; MIGOTT, 2002; LIM; SMITH; BOTTOMLEY, 2003), bem como de estudos dedicados à questão da mulher no mundo do trabalho (BESSE, 1999; MAERKER, 2000; PRIORE; BASSANEZI, 1997; ROSALDO; LAMPHERE, 1979) - além da própria experiência cotidiana -, contribuem para que se perceba a importância do gênero feminino na construção da dinâmica empreendedora do futuro nas pequenas empresas.

Mais especificamente, como já é perceptível no dia a dia de muitas empresas, as atitudes e disposições identificadas como 'femininas', conforme aponta Maerker (2000), são exemplo da reconhecida melhor capacidade das mulheres em lidar com as emoções, o que vem se tornando um diferencial competitivo - contrariando análises mais conservadoras, que concebem um mundo do trabalho marcado pela crescente tecnicidade e, portanto, com menos espaço, reforça a autora, para componentes 'intuitivos', vindo a ser marcadamente 'racionais' as áreas de atuação mais promissoras das próximas décadas.

Rev. Adm. UFSM, Santa Maria, v. 3, n. 2, p. 288-302, mai./ago. 2010 
Esse componente intuitivo é um grande diferencial das pequenas empresas que são lideradas por mulheres. A inserção delas na atividade empreendedora e gerencial é abordada em estudos, como os de Moore e Buttner (1997); Adler e Izraeli (1994); Allen e Truman (1993); Richardsen e Burke (2000). Esses autores salientam, dentre outros aspectos, as diferenças culturais e os problemas enfrentados no exercício do papel de pequenas empresárias e informam que a atenção com esse segmento se justifica pela sua proporção socioeconômica, dado que a participação feminina nos pequenos negócios atinge, até o momento, percentuais relativos a 30 ou $40 \%$ das micro e pequenas empresas em países como Estados Unidos, Canadá, Finlândia e Austrália. Conforme destaca Machado (2001), no caso brasileiro, esse percentual situa-se aproximadamente em 25\%. Pesquisa recente e declarações do Sr. Paulo Okamoto, presidente Nacional do SEBRAE, divulgada pelo Global Entrepreneurship Monitor (GEM), constatou um grande aumento da presença feminina nos novos negócios no Brasil (ADMINISTRADORES, 2010) Em 2000, apenas 29\% da população empreendedora era feminina. Já em 2003, as muIheres representaram 46\%, de um total de 14 milhões de empreendedores. No Brasil, a pesquisa contou com a colaboração do Sebrae.

Este artigo visa contribuir para o aprofundamento e sistematização do conhecimento sobre o papel das mulheres como empreendedoras de pequenas empresas e as características de sua presença, tendo dois objetivos: (a) conhecer as características pessoais de empreendedoras relacionadas à sua origem, trajetória educacional, experiência profissional e vida pessoal; e (b) a identificação de parâmetros que descrevam o papel da mulher empreendedora nas pequenas empresas.

A metodologia de pesquisa baseou-se em estudo exploratório multicasos, e o artigo está estruturado em cinco seções. A primeira é introdutória; a segunda apresenta e discute o referencial teórico/analítico sobre a inserção de mulheres empreendedoras no mercado de trabaIho; a terceira é dedicada à apresentação da metodologia de pesquisa; a quarta apresenta os resultados das pesquisas realizadas e sua análise e a quinta seção indica e apresenta algumas considerações e possibilidades para futuras pesquisas.

\section{A inserção de mulheres empreendedoras ao redor do mundo}

A entrada em larga escala das mulheres no mundo do trabalho - e particularmente no universo do empreendedorismo - trouxe mudanças significativas nos modos de se conceber as relações profissionais e as estratégias empresariais nas pequenas empresas, além de interferir nas formas de se perceber os clientes no que diz respeito às suas demandas e aspirações.

No entanto, a situação das empreendedoras ainda se encontra muito distante de ser considerada confortável, uma vez que somente a partir da década de 1980 ocorreram mudanças nos princípios de equidade entre os sexos e nas questões de ordem cultural e jurídica (SCORZAFAVE, 2001, p. 45).

Sob o aspecto histórico, uma das observações relativas à condição empreendedora atual também tem sua origem na observação de mudanças já perceptíveis há muitas décadas, sendo que foi principalmente no setor de serviços, conforme destaca Besse (1999), que tais mudanças ocorreram de forma mais significativa no padrão de emprego feminino.

O desenvolvimento de novas tecnologias e a expansão de órgãos do governo, empresas, comerciais, serviços financeiros e comunicações proporcionaram um número crescente de cargos de escritório de bom nível para mulheres com instrução, da classe média e da classe baixa ascendente. 
Cabe destacar, ainda, um aspecto particularmente controverso e que já tem sido discutido com alguma intensidade em países mais desenvolvidos neste campo: as mulheres teriam maiores dificuldades que os homens para iniciar uma atividade empreendedora, ocasionadas por preconceitos arraigados na sociedade e, em vista desta circunstância, dependeriam de apoio (institucional, governamental etc.) para participarem do universo do empreendedorismo em uma situação de maior igualdade. Esta afirmação, de Lim, Smith e Bottomley (2003), encontra-se em uma pesquisa realizada com empreendedoras (bem-sucedidas) na Escócia, no ano de 2002. Nessa pesquisa, as autoras afirmam que os resultados das atividades realizadas pelas empreendedoras poderiam ser medidos em função das políticas governamentais dedicadas à questão, como, por exemplo, a reorganização dos mecanismos de suporte aos negócios, na Escócia, em 1993/1994, que passou a visar finalidades diversas. Consequentemente, as empreendedoras foram colocadas em segundo plano pelas políticas públicas, reduzindo suas atividades. Os autores observaram a atividade de mulheres jovens e graduadas e, no período estudado, a década de 1990, houve um aumento de oportunidades para as mulheres escocesas apenas no setor industrial.

Segundo Machado (2001), se forem observados outros exemplos ao redor do mundo, pode-se afirmar que não apenas os países da Europa (destacadamente a Alemanha, Grécia e Irlanda), mas também da Ásia (especialmente o Japão) vêm-se preocupando cada vez mais com a questão específica da mulher empreendedora. Na prática, esta preocupação se traduz em programas de treinamento, subsídios governamentais e créditos diversos para pequenos negócios. Essa autora também destaca a criação na Europa, em 1991, da New Opportunities for Women (NOW), entidade que surgiu com o objetivo de:

- atuar no sentido de democratizar o acesso das mulheres ao mercado de trabalho (ainda dominado pelos homens);

- promover a conciliação entre trabalho e família, um dos maiores obstáculos observados na carreira das mulheres empreendedoras;

- promover o acesso das mulheres à educação e à qualificação profissional;

- estimular o empreendedorismo;

- incentivar a criação de empregos, a partir das próprias mulheres.

Importante notar que, nesse caso, a questão do empreendedorismo encontra-se intimamente ligada a outros aspectos, de ordem política e social, que tornam a discussão em torno do papel da mulher empreendedora muito mais complexa não por acaso. No ano 2000, a NOW selecionou 21 projetos, objetivando estimular as mulheres a enfrentarem os ainda imensos desafios que têm a superar, se quiserem obter êxito nos processos de criação, consolidação e desenvolvimento de seus empreendimentos.

No Brasil, conforme exposto na tabela 1, levando em conta o perfil dos entrevistados, os cinco estudos realizados pelo SEBRAE (apenas as empresas mais novas de cada amostra - com até 1 ano de constituição), verificou-se uma tendência de crescimento da participação dos empreendedores do gênero feminino, que passou de uma proporção de $31 \%$ no primeiro estudo, chegando até 39\% no quarto estudo, tendo, no último trabalho, retornado para 35\% do total dos entrevistados. O aumento da participação do público feminino nos quatro primeiros estudos segue uma tendência geral, já identificada por órgãos como o IBGE, de maior inserção das mulheres em todos os tipos de ocupações no mercado de trabalho. A redução no último estudo, em parte, pode estar associada a uma melhoria da economia brasileira, que, abrindo maior número de vagas de emprego, pode ter contribuído para reduzir a entrada de mulheres como proprietárias de novos empreendimentos. 
Tabela 1 - Distribuição dos empreendedores(as) entrevistados(as) por gênero (empresas com até 1 ano de constituição)

\begin{tabular}{|c|c|c|c|c|c|}
\hline Gênero/Ano & $\begin{array}{c}1995,1996 \\
\text { e } 1997\end{array}$ & 1998 e 1999 & 2000 e 2001 & 2002 e 2003 & 2004 e 2005 \\
\hline Homens & $69 \%$ & $68 \%$ & $63 \%$ & $61 \%$ & $65 \%$ \\
\hline Mulheres & $31 \%$ & $32 \%$ & $37 \%$ & $39 \%$ & $35 \%$ \\
\hline
\end{tabular}

Fonte: Observatório das MPEs do SEBRAE-SP (2008)

A tabela 2, reproduzida de Carter, Anderson e Shaw (2001), compara a participação de homens e mulheres empreendedores no Reino Unido - separados e de forma agregada - ao longo da década de 1990. As alterações são sempre avaliadas em relação aos dados da categoria do período anterior, por exemplo, a existência de 869.356 mulheres empreendedoras, em 1998, representa um acréscimo de 4.545 mulheres empreendedoras em relação as 864.811 existentes em 1997. Talvez uma análise histórica pudesse explicar os avanços nos números em alguns anos e os retrocessos, em outros anos.

Tabela 2 - Empreendedorismo e gênero no Reino Unido 1990 - 1999

\begin{tabular}{c|c|c|c|c|c|c}
\hline ANO & $\begin{array}{c}\text { Total } \\
\text { H/M }\end{array}$ & Alteração $^{1}$ & H. Empr. & Alteração & M. Empr. & Alteração $^{\mathbf{1}}$ \\
\hline $\mathbf{1 9 9 0}$ & 3571887 & & 2714637 & & 857250 & \\
\hline $\mathbf{1 9 9 1}$ & 3415842 & -156045 & 2598635 & -116002 & 817207 & -40043 \\
\hline $\mathbf{1 9 9 2}$ & 3226889 & -188953 & 2438316 & -160319 & 788573 & -28634 \\
\hline $\mathbf{1 9 9 3}$ & 3184474 & -42415 & 2384175 & -54141 & 800300 & +11727 \\
\hline $\mathbf{1 9 9 4}$ & 3300535 & +116061 & 2480490 & +96315 & 820046 & +19746 \\
\hline $\mathbf{1 9 9 5}$ & 3361262 & +60727 & 2548620 & +68130 & 812643 & -7403 \\
\hline $\mathbf{1 9 9 6}$ & 3299806 & -61456 & 2470236 & -78384 & 829570 & +16927 \\
\hline $\mathbf{1 9 9 7}$ & 3351285 & +51479 & 2486474 & +16238 & 864811 & +35241 \\
\hline $\mathbf{1 9 9 8}$ & 3280174 & -71111 & 2410818 & -75656 & 869356 & +4545 \\
\hline $\mathbf{1 9 9 9}$ & 3202371 & -77803 & 2377712 & -33106 & 824659 & -44697 \\
\hline
\end{tabular}

${ }^{1}$ Mudanças calculadas como $+/$ - em relação ao ano anterior.

\subsection{Identidade feminina e empreendedorismo}

A questão da identidade feminina no âmbito do empreendedorismo, conforme apontam Carter, Anderson e Shaw (2001), é uma das questões-chave no tocante ao problema de pesquisa apresentado neste artigo, o qual, na verdade, perpassa a maioria dos aspectos já analisados anteriormente, a começar pelas drásticas alterações nas relações de trabalho observadas na última década, pois a partir da entrada em massa da mulher no mercado de trabalho, e particularmente no mundo dos negócios, tornou-se evidente que uma nova configuração das relações profissionais, mais complexa e ainda não satisfatoriamente desvendada, instalou-se nos ambientes de trabalho. Essa novidade se revela, numa primeira observação, principalmente pelo surgimento de um ambiente competitivo que não distingue homens de mulheres - ou o faz cada vez menos. Profissionais, empreendedores ou não, disputam espaço e/ou mercado, emergindo com intensidade na busca por competência.

$E$ as mulheres, nesse embate, necessitam enfrentar - num processo de permanente desconstrução e reconstrução - muitos lugares-comuns e preconceitos que ainda se fazem 
presentes na sociedade contemporânea. É nesse contexto que Cramer, Cappelle e Silva (2001) observam que se faz necessário reconhecer, em meio ao conturbado cotidiano das profissionais, a existência de um processo por elas vivenciado que sugira a construção de uma possível nova identidade feminina - necessária na medida em que preconceitos seculares (sociais, comportamentais, etc.) resistem, apesar da já bastante evidente força do processo de participação das mulheres no mundo trabalho.

Conforme aponta Belle (1993), este processo de construção de identidade feminina seria estruturado a partir de dois elementos: por um lado, uma concepção de feminilidade que seria interiorizada por meio da educação e, de outro, as próprias normas de comportamentos existentes no mundo do trabalho. Em outras palavras, este processo corresponderia a um imenso desafio, no qual a mulher se colocaria no mundo do trabalho de modo a reafirmar suas características femininas intrínsecas e, ao mesmo tempo, absorveria elementos já caracterizados como masculinos. Numa breve reflexão, fica evidente que esta passagem descrita coloca a mulher em uma situação ambígua, desconfortável, uma vez que, na prática, trata-se de conciliar percepções e atitudes perante o mundo francamente oposto, por exemplo, frieza (normalmente atribuída ao sexo masculino) e sensibilidade.

E, como se este desafio não fosse suficiente, Cramer, Cappelle e Silva (2001) destacam que as mulheres, muitas vezes, não conseguiriam superar o que as autoras classificam como um 'sentimento de culpa' - alimentado pela família e por elas próprias -, em virtude das exigências profissionais consumirem um tempo que seria utilizado pela mulher no cumprimento de outros papéis sociais, como os de esposa ou mãe.

Assim, para se pensar no papel da empreendedora nos tempos atuais seria necessário o enfrentamento de uma complexa tarefa: pensar esta profissional em meio ao multifacetado campo das representações sociais, como indicam Cramer, Cappelle e Silva (2001), uma vez que, a partir deste elemento, seria possível interpretar o que poderia ser classificado como a 'realidade' vivenciada pelas mulheres no âmbito do trabalho.

\section{Metodologia}

Para que os objetivos estabelecidos fossem alcançados, o procedimento metodológico adotado foi a uma abordagem exploratório-descritiva, a qual, de acordo com Selltiz et al. (1974, p. 60), além de ter "como objetivo a formulação de um problema para investigação mais exata ou para a criação de hipóteses", pode ter outras funções, tais como "aumentar o conhecimento do pesquisador acerca do fenômeno [...]; o esclarecimento de conceitos; o estabelecimento de prioridades para futuras pesquisas".

Como estratégia de pesquisa, utilizou-se o estudo de casos múltiplos, em quatro empresas, sendo duas empresas do setor de serviços e duas do ramo industrial. Yin (2005) utiliza esse tipo de estratégia de pesquisa para contribuir com o conhecimento dos fenômenos individuais, organizacionais, sociais, políticos e de grupo, buscando oferecer um conjunto de critérios para a discussão teórica e para a descrição do papel da mulher empreendedora nas pequenas empresas.

A proposta do trabalho é reunir, a partir de pesquisa bibliográfica e de resultados de entrevistas, em uma amostra de casos de pequenas empresas cuja gestão era feminina, um conjunto de elementos que permitam descrever a atuação das mulheres nos segmentos dessas empresas. O esforço se voltou, em primeiro lugar, para o exame da literatura pertinente, evi- 
denciando a visão dos principais autores que discutem o conceito e o papel da mulher na pequena empresa.

Em segundo lugar, os pontos destacados a partir da revisão bibliográfica, procedimento metodológico básico, dada a natureza deste trabalho, foram reforçados levando-se em conta os resultados de pesquisas junto a pequenas empresas dirigidas por mulheres. Os principais instrumentos de coleta de dados foram a observação e as entrevistas. Foram realizadas entrevistas em profundidade, visando a não interferir na realidade, apenas interpretar fatos que influenciam os fenômenos estudados, estabelecendo correlações entre as variáveis e, necessariamente, tendo fundamentação teórica e prática.

Para analisar os dados extraídos das entrevistas, foram utilizados padrões estabelecidos pelo "Big Five Personality Model" (modelo Big Five); utilizado para identificar e analisar as considerações das entrevistadas referentes aos traços de personalidade e para o reconhecimento das influências da personalidade no desempenho dessas empreendedoras.

De acordo com Asendorpf (2004), o Big Five é um teste que mede as cinco dimensões fundamentais da personalidade. O modelo compreende cinco aspectos diferentes de personalidades, mensurados por escalas, e, quando realizado, as pessoas se autoavaliam e são encorajadas a avaliar outra pessoa, pois, conforme este método, por avaliar o outro, as pessoas tendem a realizar uma avaliação mais exata da sua própria personalidade. Para que a autoavaliação e a avaliação de outra pessoa aconteçam, foi aplicado, nas gestoras, o teste psicológico extraído do site do Big Five e traduzido para a língua portuguesa. Conforme descrito no site, este teste mede o que muitos psicólogos consideram serem as cinco dimensões fundamentais da personalidade. No teste, há 48 questões que solicitam a avaliação da pessoa que está passando pelo teste e ao mesmo tempo a pessoa escolhe outra pessoa conhecida. Além de conseguir um perfil da personalidade da pessoa que elas avaliaram, permitirá também comparar a si próprio em relação a esta pessoa em cada uma das cinco dimensões básicas de personalidade. Para tanto, no teste, foi sugerido que as participantes escolhessem alguém que elas conhecessem bem, como um amigo próximo, colega de trabalho, marido ou outro membro da família. No caso das empreendedoras, elas escolheram seus esposos ou sócios das empresas, somente a entrevistada número um escolheu seu filho.

Como destacado por Hutz et al. (1998), o modelo Big Five teve origem nos estudos da linguagem natural, realizados com vistas a encontrar traços característicos de personalidade. No início dos anos 1930, McDougall, nos EUA, sugeriu analisar a personalidade a partir de cinco aspectos (intelecto, caráter, temperamento, disposição e humor). Esses autores destacam, como origem do modelo Big Five, o sistema de Cattell para a descrição da personalidade humana, baseado em análises fatoriais de descrição de características de personalidades obtidas mediante entrevistas, questionários etc., o que constituiu a metodologia inerente a esse sistema, permitindo agrupar centenas de descrições de traços de personalidade, dando origem ao modelo Big Five.

Conforme Mc Adams (apud HUTZ et al., 1998), os cinco fatores do modelo se referem a uma série de informações fundamentais que, via de regra, se quer obter de pessoas com quem se vai interagir, por exemplo, em situações de trabalho ou que envolvem negociações. Os cinco fatores sugerem uma preocupação no sentido de se conseguir um determinado conjunto de informações sobre uma pessoa, e são, para Hutz et al. (1998), os ligados às características de perfil comportamental: a) ser ativo/dominante ou passivo/submisso; b) ser agradável/ amistoso ou desagradável/frio/distante; c) ser responsável ou negligente; d) ser imprevisível ou "normal"; e e) ser esperto ou tolo. Para este estudo, por ser considerada mais adequada ao tema empreendedorismo, foi utilizada a tradução realizada por Envick e Langford (2003), que em- 
pregaram o modelo Big Five para estabelecerem diferenças entre empreendedores e empreendedoras, no contexto dos Estados Unidos, usando como fatores ou dimensões: a) confiabilidade x instabilidade; b) extroversão $x$ introversão; c) impulsividade $x$ cautela; d) orientação para equipe $\mathrm{x}$ interesse próprio; e) praticidade $\mathrm{x}$ originalidade.

Além da aplicação em muitos artigos acadêmicos (BRANDSTÄTTER, 1997; DIGMAN, 1990; SALGADO, 1997; COLLINS; GLEAVES, 1998; SMITH; SMITS; HOY, 1992), entre outros, existe, atualmente, um esforço sistemático de teste e aperfeiçoamento do modelo, com acompanhamento de pesquisadores localizados em universidades americanas, como se pode constatar no site http://www.outofservice.com.bigfive.

Esse método permite comparar a si próprio em relação a outras pessoas em cada uma das cinco dimensões básicas de personalidade. Nessa metodologia de avaliação, não existe resposta "certa" ou "errada". Para a apuração das respostas e formulação das análises, as respostas foram submetidas ao site do Big Five (2005), assim quando as empreendedoras enviaram as respostas, estas eram submetidas ao site para a apuração dos resultados.

A orientação básica para analisar os dados coletados se baseou em duas abordagens: uma 'vertical' e outra 'horizontal'. A abordagem vertical corresponde à apresentação dos dados coletados em campo pela apresentação e descrição de cada empreendedora por meio do roteiro de pesquisa. Assim, foram descritas as características pessoais, comportamentais e a atuação executiva de cada uma das quatro empreendedoras separadamente. Exprimindo essa ideia de outra forma, a abordagem vertical descreve os casos estudados um após o outro.

Em seguida, utilizou-se a abordagem denominada horizontal, que consistiu na comparação das respostas fornecidas por todas as empreendedoras entrevistadas a cada questão a elas formulada. Esses procedimentos conduziram ao alcance de grande riqueza e profundidade de análise, permitindo a produção de comparações que permitiram agrupar as empreendedoras segundo determinadas categorias e características.

Para atender os objetivos deste estudo, foram escolhidas, como estudo de múltiplos casos, quatro empreendedoras, atuantes em dois segmentos econômicos distintos (serviços e indústria), com no mínimo cinco anos de existência no mercado, independentemente da quantidade de sócios, ainda tendo em comum que se tratava do primeiro empreendimento das entrevistadas. Outra característica para a escolha da empreendedora era que sua atuação fosse em negócios que são considerados como de domínio do sexo masculino (oficina mecânica, indústria têxtil, informática e editora). A localização dos empreendimentos também foi levada em consideração, já que todas deveriam ser da cidade de São Paulo.

\section{Resultados da pesquisa}

Neste item, apresentam-se, primeiramente, as empresas que representam os casos estudados e, em seguida, os resultados da pesquisa do perfil da mulher empreendedora.

\subsubsection{Apresentação dos múltiplos casos estudados}

a) Empresa de serviços automotivos

A empresa se localiza na cidade de São Paulo e atua na prestação de serviços automotivos voltados à funilaria geral. Nessa empresa, a empreendedora (38 anos de idade, divorciada e mãe de um filho, segundo grau completo de instrução) iniciou sua atividade a partir da neces- 
sidade de recuperar o investimento feito pelo ex-marido em um negócio próprio - aproximadamente 40 dias após abrir a oficina mecânica, o então novo pequeno empresário estava propenso a fechar o negócio, por falta de habilidade em comunicação. Esta foi sua primeira e única experiência como empreendedora. No entanto, após três anos de funcionamento da empresa, a sociedade e o casamento foram desfeitos e, atualmente, apenas a proprietária administra todo o negócio.

A empresa tem sete anos de existência e atua na prestação de serviços automotivos de mecânica, pintura em carros de diversas marcas e modelos, sendo eles nacionais ou importados - contando com 12 empregados. Todos são profissionais já formados e especializados em suas áreas de atuação e com ampla experiência no mercado - o que acabou gerando um quadro de funcionários com uma faixa etária mais avançada do que a média que se costuma encontrar no mercado brasileiro. Ou seja, nesta empresa, dá-se preferência a profissionais acima de 40 anos de idade, pelo fato da proprietária acreditar que, pela experiência dos mesmos, os trabalhos são executados de maneira mais rápida, eficiente e com menos custos.

b) Empresa de consultoria

A segunda empresa é do ramo de Consultoria e Treinamento em Informática, e a entrevistada foi uma de suas sócias-proprietárias (35 anos de idade, casada, um filho, pedagoga, pósgraduação em Administração Escolar).

A escolha desta organização ocorreu devido ao fato de a maioria dos seus clientes serem empresas governamentais, exigindo, assim, que passasse sempre por processos de licitação - ramo dominado por homens.

No decorrer da entrevista, ficou claro, que apesar do domínio masculino no setor, a competência é o que prevalece. A primeira fase da empresa foi marcada por serviços de treinamento e, atualmente, presta consultorias a diversas empresas em todo o território nacional, a exemplo da Companhia do Metropolitano de São Paulo, Centro de Campinas (CDQD), SPTrans, EMTU, Faculdade Trevisan e Prefeitura de Itatiba.

As atividades da empresa iniciaram-se no ano de 1999, e seu ramo é a consultoria na área de informática - sua atuação compreende todo o território brasileiro, e seu ponto forte são os treinamentos in loco nas empresas. Sua principal atuação é na área de Open Office, que, de acordo com o depoimento da entrevistada, vem ganhando muito espaço no mercado brasileiro, principalmente nas empresas governamentais, pelo fato destas não pagarem licenças para uso do sistema.

c) Indústria química

A empresa está localizada em São Paulo e atua no setor químico-industrial. Criada pelo pai da atual proprietária, em 1966, contava na época com 40 empregados. Além de suas atividades na empresa, a entrevistada (58 anos de idade, casada, 2 filhos, Engenheira Química, Direito cursado até o terceiro ano e pós-graduação em Administração) participa da diretoria de alguns conselhos de classe - representantes do seu ramo de atuação - o que amplia significativamente seus relacionamentos com concorrentes e fornecedores, além de contribuir para os resultados positivos de sua atuação como empreendedora.

Uma das características do seu quadro de funcionários - a exemplo do observado anteriormente - é a presença de muitos empregados na faixa de 40 anos de idade, o que facilita, na visão da empreendedora, todo o processo produtivo da fábrica. 


\section{d) Editora}

Localizada em São Paulo, a empresa atua em três linhas editoriais: autoajuda, educação e gestão. Atenta à evolução do mercado editorial e às tendências sociais e de comportamento no Brasil e no exterior, a Editora está presente nos principais eventos do calendário literário nacional e, frequentemente, busca novidades em feiras internacionais.

A entrevistada (49 anos de idade, três filhos, Arquiteta, mestre em Administração e pósgraduada em Marketing, fluência em inglês e alemão) é sócia-proprietária da Editora. Sua experiência profissional anterior foi no ramo da construção civil. Foi convidada por seu irmão, fundador da editora, a ajudá-lo a administrar a empresa. Mesmo sem entender do negócio, enfrentou todos os desafios, buscando ajuda inclusive entre seus concorrentes - muitos dos quais, conforme ela afirma, são contatos próximos e atuam de modo exemplarmente ético (uma distinção própria do mercado editorial, de acordo com a entrevistada).

Sua decisão em entrar para esse ramo de atuação não ocorreu por motivos financeiros, mas por realização profissional, pois iria coordenar uma empresa e colocar em prática todos os seus projetos. Além de suas atividades na empresa é, atualmente, vice-presidente da Associação Brasileira do Livro, tendo que se ausentar por diversas vezes do país para representar a instituição em entidades e eventos internacionais.

A editora iniciou suas atividades no ano de 1984, estando, portanto, com 25 anos de atividade, e conta com 40 pessoas em seu quadro de funcionários. É uma empresa constituída sob a forma limitada e possui dois sócios: a entrevistada e seu irmão.

\subsubsection{Análise dos resultados}

O presente trabalho caracteriza-se como estudo de múltiplos casos, com uma única unidade de análise: a pessoa do empreendedor. Esse tipo de estudo foi considerado o mais adequado para atender à questão e aos objetivos de pesquisa que, em sua forma geral, visam investigar a atuação profissional de mulheres empreendedores brasileiras em seus mercados.

No que diz respeito, especificamente ao primeiro objetivo, "conhecer as características pessoais de empreendedoras relacionados à sua origem, trajetória educacional, experiência profissional e vida pessoal".

Observou-se que a maioria das entrevistadas possuem graduação e, nos casos 2, 3 e 4, pós-graduação e fluência em outro idioma. As entrevistadas são casadas e têm filhos, apenas a representante da empresa 1 é divorciada, e sua formação foi até o ensino médio. Todas tiveram empregos anteriores, mas não como empreendedoras.

O quadro 1 apresenta alguns resultados obtidos sobre o desempenho dessas mulheres referentes à organização e confiabilidade no setor em que atuam, através do método do Big Five.

\begin{tabular}{|c|c|c|}
\hline \multicolumn{3}{|c|}{ Confiabilidade $x$ Instabilidade } \\
\hline \multicolumn{3}{|c|}{$\begin{array}{l}\text { Pessoas com pontuaçốes altas tendem a ser de confiança, bem organizadas, disciplinadas, cuidadosas; } \\
\text { pontuaçóes baixas sắo caracterizadas a pessoas desorganizadas, em que nấo se podem confiar, negligentes. }\end{array}$} \\
\hline Nome & Percentual & Descrição \\
\hline Empresa 1 & I-O- $47 \%$ & Não é organizado nem desorganizado. \\
\hline Empresa 2 & $\mathbf{I}-\mathbf{I} 69 \%$ & Bem organizado e de confiança. \\
\hline Empresa 3 & I & Não é organizado nem desorganizado. \\
\hline Empresa 4 & $1 \longrightarrow-186 \%$ & Muito bem organizado/alguém que possa se contar. \\
\hline
\end{tabular}

Quadro 1 - Resultado da análise dos parâmetros Confiabilidade x Instabilidade

Fonte: Resultado extraído do site do Big Five (2005) após alimentá-lo com as respostas das entrevistadas. Realizado em 22/01/2005.

Rev. Adm. UFSM, Santa Maria, v. 3, n. 2, p. 288-302, mai./ago. 2010 
Assim, no item organização, as mulheres apresentaram forte tendência à organização. Analisando a partir das áreas de atuação (serviços e indústria), verificou-se que as empreendedoras atuantes na prestação de serviços apresentaram um percentual mais elevado no critério Confiança (Empresa 2 e 4). Pode-se observar que as empresas que possuem tais resultados têm em comum um contato mais direto com seus clientes, o que leva as empreendedoras a serem mais disciplinadas e cuidadosas, demonstrando mais confiança e competência no trabalho que realizam.

O quadro 2 refere-se ao item extroversão; neste caso, observa-se uma tendência das mulheres serem extrovertidas.

\begin{tabular}{|c|c|c|}
\hline \multicolumn{3}{|c|}{ Extroversão x Introversão } \\
\hline \multicolumn{3}{|c|}{$\begin{array}{l}\text { Pontuações altas são características de pessoas sociáveis, amigáveis, que gostam de se divertir e que gostam } \\
\text { de falar muito; pessoas com baixa pontuação tendem a serem introvertidas, reservadas, inibidas, caladas. }\end{array}$} \\
\hline Nome & Percentual & Descrição \\
\hline Empresa 1 & 1-191\% & Muito extrovertido, sociável e dinâmico. \\
\hline Empresa 2 & $79 \%$ & $\begin{array}{l}\text { Relativamente sociável e gosta da companhia de outras } \\
\text { pessoas. }\end{array}$ \\
\hline Empresa 3 & $\longrightarrow 86 \%$ & Muito extrovertido, sociável e dinâmico. \\
\hline Empresa 4 & 1 & Muito extrovertido, sociável e dinâmico. \\
\hline
\end{tabular}

Quadro 2 - Resultado da análise dos parâmetros Extroversão x Introversão

Fonte: Resultado extraído do site do Big Five (2005) após alimentá-lo com as respostas das entrevistadas. Realizado em 22/01/2005.

Na análise por ramo de atuação, verificou-se que o maior nível de socialização estava nas pessoas atuantes na indústria, em comparação às pessoas que atuavam nas empresas prestadoras de serviços, mas as diferenças consideradas são muito ínfimas.

No que se refere à relação Impulsividade X Cautela, conforme a análise do quadro 3, ficou claro que, em sua grande maioria, as empreendedoras tendem a ser pessoas calmas deste modo, potencialmente abertas ao diálogo e capazes de administrar conflitos e situações estressantes (sempre presentes no cotidiano das atividades profissionais do empreendedor).

\begin{tabular}{|l|l|}
\hline \multicolumn{2}{|l|}{ Impulsividade x Cautela } \\
\hline Pontuações altas são características de pessoas que tendem a serem nervosas, tensas, inseguras, que se \\
preocupam muito; pessoas com baixa pontuação tendem a serem calmas, seguras de si mesma s, \\
emocionalmente estáveis.
\end{tabular}

Quadro 3 - Resultado da análise dos parâmetros Impulsividade x Cautela

Fonte: Resultado extraído do site do Big Five (2005) após alimentá-lo com as respostas das entrevistadas. Realizado em 22/01/2005.

Rev. Adm. UFSM, Santa Maria, v. 3, n. 2, p. 288-302, mai./ago. 2010 
Analisando o ramo de atuação, percebe-se que a empreendedora da empresa 1 é destoante das demais, isso provavelmente ocorre por causa da instabilidade do mercado em que atua e pelo fato de que essa empreendedora administra sozinha o negócio. As demais mulheres entrevistadas têm equipes de apoio que dão suporte às decisões tomadas, além de terem a quem delegar atividades corriqueiras para melhor se concentrarem no processo decisório.

A análise do quadro 4 destaca a preocupação das empreendedoras entrevistadas com atenção aos sentimentos dos outros. Todas são consideradas pessoas generosas, educadas e auxiliadoras, demonstrando que ser empreendedor não significa ser egoísta e só visar seu próprio crescimento, como apontado nos mitos de Farrel (1993).

\begin{tabular}{|c|c|c|c|}
\hline \multicolumn{4}{|c|}{ Orientação para a equipe $\mathrm{x}$ interesse próprio } \\
\hline \multicolumn{4}{|c|}{$\begin{array}{l}\text { Pontuações altas são características de pessoas que tendem a serem boas, simpáticas, complacente } \\
\text { corteses; pessoas com baixa pontuação tendem a serem críticas, arrogantes, insensíveis e frias. }\end{array}$} \\
\hline Nome & Percentual & & Descrição \\
\hline Empresa 1 & 1 & $79 \%$ & Tende a considerar os sentimentos dos outros. \\
\hline Empresa 2 & 1 & $63 \%$ & Tende a considerar os sentimentos dos outros. \\
\hline Empresa 3 & -1 & $83 \%$ & Pessoa generosa, cortês e auxiliadora. \\
\hline Empresa 4 & -1 & $74 \%$ & Tende a considerar os se ntimentos dos outros. \\
\hline
\end{tabular}

Quadro 4 - Resultado da análise dos parâmetros Orientação para a equipe x interesse próprio

Fonte: Resultado extraído do site do Big Five (2005) após alimentá-lo com as respostas das entrevistadas. Realizado em 22/01/2005.

Com relação às áreas de atuação, tanto as empreendedoras que atuam na prestação de serviços como na indústria ficaram com pontuação acima da média. Mas pode-se concluir que, independente da área de atuação, as empreendedoras entrevistadas são pessoas preocupadas com a satisfação das outras pessoas em suas atuações profissionais.

Isso fica evidenciado também no fato de que em todas essas empresas administradas por mulheres há preferências por funcionários acima dos 40 anos. Elas valorizam a experiência desses profissionais e reconhecem seu comprometimento com a empresa.

A comparação dos resultados obtidos nas análises das características Impulsividade $\mathrm{x}$ Cautela e Orientação para a equipe $x$ Interesse próprio, remete ao estudo apontado realizado por Scorzafave (2001) - no qual se afirma que mulheres empreendedoras, muito provavelmente, terão que demonstrar, além das aptidões comumente associadas aos homens (racionalidade, capacidade de decisão, agressividade na condução dos negócios, liderança etc.) outras características importantes (e historicamente ligadas às atividades femininas, particularmente na administração do cotidiano doméstico). Ou seja, essas mulheres têm de demonstrar capacidade de adaptação às situações de controle e pressão social intensos ou, ainda, a habilidade para agregar pessoas e produzir resultados.

A análise dos resultados dos parâmetros Praticidade x Originalidade mostrou que, dentre as quatro gestoras, duas aproveitam novas experiências e conseguem enxergar novas coisas com diferentes perspectivas. Uma é relativamente aberta a novas experiências, e somente uma 
possui uma forte tendência a não procurar novas experiências. Essa diferenciação provavelmente ocorra devido ao ramo de atuação das atividades das entrevistadas.

Importante ressaltar, em relação aos resultados do quadro 5, que a representante da empresa 3 atua no setor químico tradicional, o que, de fato, dificulta a busca por novas experiências, diferentemente das demais representantes das empresas pesquisadas (1, 2 e 3), que atuam em um mercado mais dinâmico, em que novas experiências e perspectivas fazem parte do mercado em que atuam. Considerando o ramo de atuação, observa-se um empate, com duas empreendedoras de cada ramo abaixo da média esperada e duas acima.

\begin{tabular}{|c|c|c|c|}
\hline \multicolumn{4}{|c|}{ Praticidade $x$ Originalidade } \\
\hline \multicolumn{4}{|c|}{$\begin{array}{l}\text { Pessoas com pontuações altas tendem a serem originais, criativas, curiosas e complexas. Pessoas com } \\
\text { pontuações baixas são características de pessoas convencionais, simples, com interesses não muito variados } \\
\text { e pouco criativos. }\end{array}$} \\
\hline Nome & Percentual & & Descrição \\
\hline Empresa 1 & 1 & $65 \%$ & Relativamente aberto a novas experiências. \\
\hline Empresa 2 & & $90 \%$ & $\begin{array}{l}\text { Aproveita novas experiências e consegue enxergar novas coisas } \\
\text { com diferentes perspectivas. }\end{array}$ \\
\hline Empresa 3 & & $41 \%$ & Geralmente não procura por novas experiências. \\
\hline Empresa 4 & -1 & $88 \%$ & $\begin{array}{l}\text { Aproveita novas experiências e consegue enxergar novas coisas } \\
\text { com diferentes perspectivas. }\end{array}$ \\
\hline
\end{tabular}

Quadro 5 - Resultado da análise dos parâmetros Praticidade x Originalidade

Fonte: Resultado extraído do site do Big Five (2005) após alimentá-lo com as respostas das entrevistadas. Realizado em 22/01/2005.

\section{Considerações finais}

O estudo realizado proporcionou a confirmação de algumas proposições inicialmente levantadas e, por outro, possibilitou que novos dados pudessem ser explicitados. Considerando que dentre os principais pontos comumente citados em discussões de gênero está a questão da desigualdade, é pertinente observar que no caso das atividades empreendedoras, as dificuldades parecem não escolher sexo. Durante a pesquisa realizada com essas mulheres ficou evidente que os obstáculos são inúmeros e, muitas vezes, aparentemente insolúveis. No entanto, todas as empreendedoras entrevistadas mostraram uma marca comum: a determinação para perseguir objetivos, alcançar metas e superar dificuldades.

Por outro lado é inegável que a vida particular das empreendedoras foi afetada de modo diferenciado. Também é oportuno observar que questões econômicas e sociais de maior amplitude apresentam um peso de grande importância, a exemplo da empreendedora que iniciou suas atividades apenas para recuperar um capital investido por seu marido (Empresa 1). Fica evidente, neste caso, que a atitude empreendedora não foi condicionada pelo fator gênero, mas por uma necessidade econômica: a superação da condição econômica desfavorável como mola propulsora às ações empreendedoras.

Também ficou patente o nível de profissionalização alcançado por estas pessoas, ainda que ao custo de anos de prática da conhecida dinâmica erro-acerto. Essas gestoras apresentaram alto nível de conhecimento de seu negócio e, principalmente, disposição para crescer profissionalmente, ainda que existam inúmeras limitações, próprias do contexto brasileiro. 
Conforme pôde ser verificado, as empreendedoras entrevistadas apresentaram trajetórias nitidamente distintas, níveis de escolaridade igualmente diversos, além de suas vidas particulares mostrarem inúmeros e singulares perfis. Contudo suas trajetórias mostram sempre o aspecto da superação de limites e a determinação de se construir o novo. Essas profissionais têm em comum o perfil inovador, inquieto, que sempre busca construir o futuro, e jamais espera que este aconteça por si.

Além disso, com relação ao chamado Modelo Big Five, foram identificadas algumas distinções importantes: mostraram clara tendência à organização, indicadores de confiabilidade representativos, forte tendência à extroversão, autoconfiança e bom auto-controle - potencialmente abertas ao diálogo e capazes de administrar conflitos e situações presentes no cotidiano. A análise destacou também que as empreendedoras entrevistadas tendem a considerar com atenção os sentimentos dos outros. Em relação aos resultados das análises das características Impulsividade/Cautela e Orientação para a equipe/Interesse próprio, pôde-se perceber que as empreendedoras conseguem visualizar oportunidades para novos projetos e perspectivas de acordo com o mercado em que atuam.

Com relação à proposição "conciliar atividade empreendedora e vida particular é um desafio para as mulheres", ficou destacado que este fator ainda pesa sobremaneira para as mulheres, particularmente no que diz respeito ao convívio e educação dos filhos.

Ainda que os resultados apresentados neste estudo, por seu perfil exploratório, apresentem limitações que impedem derivações para universos mais amplos, eles contribuem para um maior conhecimento do empreendedorismo, abrindo portas para futuros estudos tipo survey, com amostra representativa, cujos resultados possam representar o perfil do universo. Para isso, o esforço aqui empreendido pode ser uma base para o levantamento de pressupostos e/ou hipóteses que embasem estudos com métodos quantitativos capazes de iluminar novos aspectos das questões aqui analisadas. Seria também pertinente recomendar novos estudos comparativos que tragam informações relacionadas a inúmeras outras questões próprias do universo do empreendedorismo e que não foram aqui abordadas.

\section{Referências}

ADLER, N.J., IZRAELI, D. N. Women in magagement worldwide. New York: M.E. Sharp, 1994.

ADMINISTRADORES. Número de mulheres empreendedoras teve forte alta. Disponível em: <http:// www.administradores.com.br/informe-se/informativo/numero-de-mulheres-empreendedoras-teve-forte-alta/28/>. Acesso em: 28 abr. 2010.

ALLEN, S.; TRUMAN, J. M. Women entrepreneurs. Business \& Economics. London: New Fetter Lane, 1993.

ASENDORPF, J. B. Psychologie der persönlichkeit (3. Aufl.). Berlin: Springer, 2004.

BELLE, F. Executivas: quais as diferenças na diferença. In: CHANLAT, J.-F. (Coord.). O indivíduo nas organizações. São Paulo: Atlas, 1993. p.195-231.

BESSE, S. K. Modernizando a desigualdade: reestruturação da ideologia de gênero no Brasil (1914-1940). São Paulo: USP, 1999.
BIG FIVE. Disponível em: <http:// www.outofservice.com/bigfive $>$. Acesso em: 22 jan. 2005.

BRANDSTÄTTER, H. Becoming an entrepreneur: a question of personality structure? Journal of Economic Psychology, v. 18, p. 157-177, 1997.

CARTER, S.; ANDERSON, S.; SHAW, E. Women's business ownership: a review of the academic, popular and internet literature. Department of Marketing. University of Strathclyde/Glasgow. August 2001. Disponível em: <http://business.king.ac.uk/ research/kbssbs/womsbus.pdf. > . Acesso em: 14 jul. 2004.

CRAMER, L.; CAPPELLE, M. C. A.; SILVA, Á. L. Inserção da mulher no mundo dos negócios: construindo uma identidade. 2001. Disponível em: <http:/ /www.ufop.br/ichs/conifes/anais/OGT/ ogt1301.htm>. Acesso em: 14 jul. 2004. 
COLLINS, J. M. R.; GLEAVES, D. H. Job aplicants, and the five-facotr model of personality impliocations for black psychology, industrial/organizational psychology, and the five-factor theory. Journal of Applied Psychology, v. 83, n. 4, p. 531-544, 1998.

DIGMAN, J. M. Personality structure: emergence of the five-factor model. Annu Rev Psychol, v. 41, p. 417-440, 1990.

ENVICK, B. R.; LANGFORD, M. The big-five personality model: comparing male and female entrepreneurs. Academy of Entrepreneurship Journal, v. 9, n. 1, 2003. Disponível em: $<$ www.alliedacademies.org/entrepreneurship/aej91-2.pdf > . Acesso em: 28 ago. 2004.

FARREL, L. C. Entrepreneurship: fundamentos das organizações empreendedoras. Trad. Heraldo da Silva Tino. São Paulo: Atlas, 1993.

GRZYBOVSKI, D.; BOSCARIM, R.; MIGOTT, A. M. B. Estilo feminino de gestão em empresas familiares gaúchas. Revista de Administração Contemporânea, Rio de Janeiro, v. 6, n. 2, p. 185-207, maio/ago. 2002.

HUTZ, C. S. et al. O desenvolvimento de marcadores para a avaliação da personalidade no modelo dos cinco grandes fatores. Psicol. Reflex. Crit., Porto Alegre, v. 11, n. 2., 1998.

JORNAL HOJE. Força dos novos empresários. Disponível em http://g1.globo.com/jornal-hoje/noticia/ 2010/04/forca-dos-novos-empresarios.html. Acesso em 19/04/2010.

LIM, S.; SMITH, K.; BOTTOMLEY, C. Successful graduate female entrepreneurs: the scottish experience. Paper. In: ANNUAL CONFERENCE OF SMALL ENTERPRISE ASSOCIATION OF AUSTRALIA AND NEW ZEALAND, 16., 2003. Disponível em: <http://www.cecc.com.au/programs/ resource_manager/accounts/seaanz_papers/ 15FeiLimSmithBottomly.pdf>. Acesso em: 14 jul. 2004.

MACHADO, H. P. V. Empreendedorismo, gênero e políticas públicas. In: EGEPE, 2., 2004, Londrina. Anais eletrônicos... Londrina, 2001. p. 378-393. Disponível em: <http://www.dad.uem.br/egepe2/ EMP2001-50.pdf. >. Acesso em: 26 abr. 2004.
MAERKER, S. Mulheres de sucesso: os segredos das mulheres que fizeram história. São Paulo: Infinito, 2000.

MOORE. D. P ; BUTTNER, E. H. Women entrepreneurs. London: Sage, 1997.

PRIORE, M. Del; BASSANEZI, C. (Coord.). História das mulheres no Brasil. 2. ed. São Paulo: Contexto, 1997.

RICHARDSEN, A. M.; BURKE, R. Women entrepreneurs and small business owners in Norway and Canada. In: DAVIDSON, M.J.; BURKE. R. Women in management current research. v. II. London: Dage, 2000.

ROSALDO, M. Z.; LAMPHERE, L. (Coord.). A muIher, a cultura e a sociedade. Rio de Janeiro: Paz e Terra, 1979.

SALGADO, J. F. The five factor model of personality and job performance in the european community. Journal of Appied Psychology, v. 82, n. 1, p. 30-43, 1997.

SCORZAFAVE, L.G. D. da S. A evolução e os determinantes da participação feminina no mercado de trabalho brasileiro. 2001. Dissertação (Mestrado em Teoria Econômica)- Faculdade de Economia, Administração e Contabilidade-Universidade de São Paulo, São Paulo, 2001.

SEBRAE. A mulher tem condições de ser empreendedora? Saiba mais sobre o seu negócio. Disponível em: <http://www.sebraepr.com.br/servlet/ page? pageid $=407 \&$ dad $=$ portal30\&_schema $=$ PORTAL30\&p_codigo $=248>$. Acesso em: 18 maio 2004.

SEBRAE. Relatório dos 10 Anos de monitoramento da sobrevivência e mortalidade de empresas São Paulo (Estado). Serviço de Apoio às Micro e Pequenas Empresas / SEBRAE-SP. São Paulo: SEBRAE-SP, 2008.

SELLTIZ, C. et al. Métodos de pesquisa nas relações sociais. Tradução de Dante Moreira Leite. 3. ed. São Paulo: Ed. da USP, 1974. 674 p.

SMITH, P. L; SMITS, S. J.; HOY, F. Female business owners in industries traditionally dominated by males. A Jounal of Research, v. 26, n. 11/12, 1992.

YIN, R. K. Estudo de caso: planejamento e métodos. 3. ed. Porto Alegre: Bookman, 2005. 